\title{
Extremely fast supercooling of water in the anti-Jovian hemisphere of Europa: A speculative model for the fracturing pattern and ascent of brines along cracks
}

\author{
Roberto Oyarzun \\ Cristobal Viedma \\ Departamento de Cristalografía y Mineralogía, Facultad de Ciencias Geológicas, \\ Universidad Complutense, 28040 Madrid, Spain \\ Cristina de Ignacio \\ Departamento de Petrología y Geoquímica, Facultad de Ciencias Geológicas, \\ Universidad Complutense, 28040 Madrid, Spain
}

\begin{abstract}
The anti-Jovian hemisphere of Europa (the hemisphere opposite the one facing Jupiter) displays a complex array of fractures, including roughly concentric and arcuate ones. The geometry of this intriguing pattern on the icy surface of Europa resembles the textural features displayed by perlitic volcanic glass. We argue that fast cooling of a rhyolitic magma may serve as an analogue for fast supercooling of water leading to formation of amorphous ice (glassy water). We envisage two possible scenarios for ice melting and subsequent extremely fast supercooling: (1) massive subglacial volcanic activity or (2) a large impact on the anti-Jovian hemisphere. We suggest that extremely fast formation of amorphous ice on Europa would result in a fracture pattern geometrically equivalent to that observed in perlitic glass. Fast supercooling of water will initially lead to brine retention in the ice phase; however, after some time these brines would be laterally rejected toward fractures. Furthermore, as solidification progresses downward, a shrinking ocean would increase brine concentration. These brines would eventually escape to the surface via the fracture network. Finally, high-pressure crystallization of salts within fractures may provide an efficient mechanism for differential plate separation, horizontal movement, and formation of new fractures.
\end{abstract}

Keywords: Europa, anti-Jovian, glassy water, supercooling, fractures, brines.

\section{INTRODUCTION}

The highly fractured anti-Jovian hemisphere of Europa displays an intricate pattern of geologic features at different scales (Fig. $1 \mathrm{~A}$ and 1B), including linear, curved, and arcuate fractures, wedge-shaped bands, and icy plates, among others. Greeley et al. (1998a) and Prockter et al. (1999) reviewed the geology of the region, and offered some insights into the causes of such complex arrays of roughly concentric and arcuate features, approximately centered at $20^{\circ} \mathrm{S}, 200^{\circ} \mathrm{W}$. As noted by Greeley et al. (1998a), the complexity of the anti-Jovian hemisphere makes interpretation of it difficult in terms of simple global contraction (Helfenstein and Parmentier, 1983), global expansion (Finnerty et al., 1981), polar wandering (Ojakangas and Stevenson, 1989), tidal stresses induced by the eccentricity of the orbit (e.g., Helfenstein and Parmentier, 1983), or combinations of these models. We propose that the unlikely combination of tectonic features present on the anti-Jovian hemisphere strongly resembles what is found in an unexpected material, perlite, a volcanic glass with abundant arcuate and gently curved cracks (Fig. 1C and 1D) that form in response to quenching and hydration (McPhie et al., 1993; Davis and McPhie, 1996). Although this comparison might seem odd, we suggest that fast solidification of a rhyolitic magma and subsequent fracturing may provide insights into the nature and origin of the tectonic features found in the anti-Jovian hemisphere of Europa; fast solidification of water may have led to formation of amorphous ice on the anti-Jovian region. The structural behavior of this material may in turn resemble, in some relevant aspects, that of volcanic glass (Fig. 1).

\section{GLASSY WATER AND GLASSY ROCKS}

We are used to thinking of solid water in terms of classic hexagonal ice; however, this is just one variety among 10 polymorphic phases of crystalline ice (Poirier, 1982). If water is cooled fast enough, it forms a "glass" (Debenedetti, 1998). There are two glassy forms of water, lowand high-density amorphous ice (Mishima and Stanley, 1998). Low-density amorphous ice is generated by extremely fast supercooling of water vapor. Glassy water exists as frost in interstellar dust and in comets (Jenniskens et al., 1995; Debenedetti, 1998; Mishima and Stanley, 1998). We argue that it may also form part of the icy crust of Europa. Another "glassy" material, perlite, is defined as a volcanic glass in which there are abundant, delicate, intersecting, arcuate, and gently curved cracks (Fig. 1C and 1D) that surround cores of intact glass (McPhie et al., 1993). Under favorable conditions, outcrop-scale perlite (macroperlite) may form (McPhie et al., 1993). Davis and McPhie (1996) reviewed the hypotheses for the origin of perlite fracturing. The debate centers on hydration (e.g., Ross and Smith, 1955; Friedman and Smith, 1958) and cooling contraction (Marshall, 1961; Yamagishi and Goto, 1992) as the two possible mechanisms for perlitic fracturing. The study of Davis and McPhie (1996) on the Silver Hills dike (Queensland, Australia), an originally glassy body with relict perlitic structures, offers new insights into this debate. Davis and McPhie (1996) concluded that the long and cross fractures can be interpreted as the result of quench fracturing, whereas the typical perlitic fractures formed in response to strain associated with quenching and volume change. Similar results have been obtained in laboratory experiments with artificial glasses (Bartenev, 1970), experiments that result in arcuate and straight cracks. Despite the numerous investigations, accurate data concerning the shape, dimension, and number of cracks are extremely limited (Bartenev, 1970). Nonetheless, fast cooling and the isotropic nature of glasses seem to be causes of arcuate cracking. In other words, unlike crystalline solids, glasses will not break along preferential directions. 

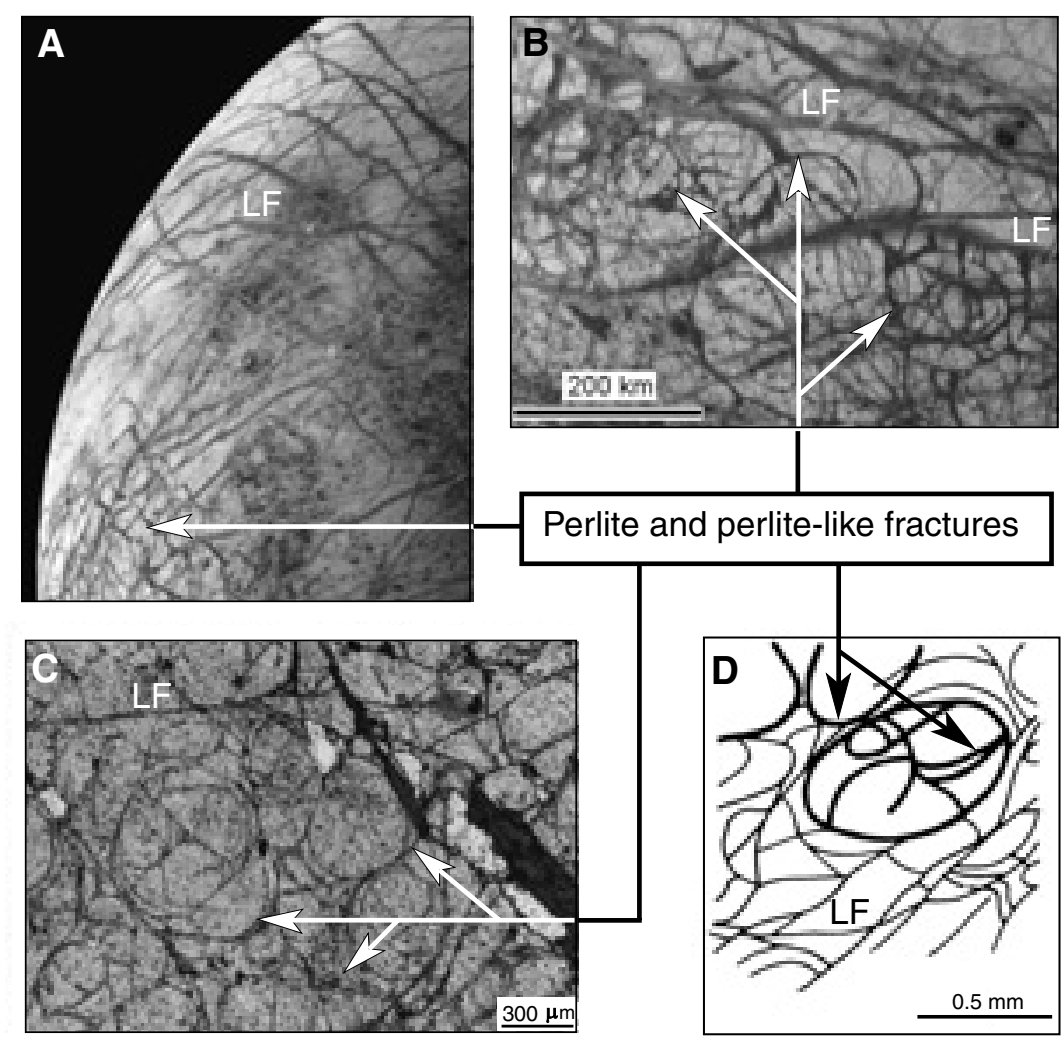

Figure 1. Fracturing on Europa and in perlitic volcanic glass. A: Part of Europa (Students for the Exploration and Development of Space, 2000). Note curved linear fractures in upper half of image. B: Part of NASA image PIA00578 (Galileo). Note arcuate, concentric fracturing pattern. C: Perlitic volcanic glass (McPhie et al., 1993). D: Sketch depicting fracturing in perlitic volcanic glass (modified after Allen, 1988). LF-long fractures.

\section{MODEL FOR THE ANTI-JOVIAN HEMISPHERE}

We suggest that the intricate pattern of fractures of Europa's anti-Jovian hemisphere results from ice melting and subsequent abrupt solidification of water into glassy ice. There are striking similarities between the pattern of fracturing in the anti-Jovian hemisphere and the observed two-dimensional cracking pattern in perlitic glasses (Fig. 1), although the environments of ice and perlite formation are considerably different, as is the scale. However, if water solidification is extremely rapid, likely for an environment such as Europa (surface temperatures in the range 100-120 K; e.g., McCord et al., 1998), then the passage from liquid (and/or vapor) to solid may resemble in some key aspects the solidification of molten rhyolite to perlitic glass in submarine environments. What would cause such a process? In order to generate low-density amorphous ice, water vapor must be supercooled extremely fast (Mishima and Stanley, 1998). We envisage two scenarios in which ice melting, formation of water vapor, and subsequent generation of glassy ice might occur. Scenario 1 involves massive volcanic activity, whereas scenario 2 involves a large impact in the anti-Jovian hemisphere of Europa.
A crucial point relates to the existence of volcanism under the icy surface of Europa. There is no indication that volcanism does not exist within Europa. Furthermore, although some authors (e.g., Carlson et al., 1999) have suggested, among other hypotheses, an exogenic source (Jovian plasma) for the sulfur compounds found on the surface of Europa, the alignment of "non-ice" material along fractures (e.g., McCord et al., 1998) strongly suggests that the origin of the sulfur compounds may be endogenic. McCord et al. (1998) proposed that Europa may sustain volcanic or hydrothermal activity, which would be the source of sulfate brines that are extruded onto the surface. A terrestrial analogue of subglacial volcanic activity is provided by the eruption of the Bárdarbunga under the Vatnajökull ice sheet (Iceland) in 1996 (Müschen et al., 1997); volcanic activity began on September 30, and by October 1 a major collapse cone had formed on the surface of the 450-600-m-thick ice sheet (Fig. 2). In the early morning of October 2 , the eruption finally broke through the ice (Halldórsson, 2000).

Prockter et al. (1999) proposed that the entire stratigraphic column of the anti-Jovian region is relatively recent. They suggested that the thermal state of the lithosphere has changed over time as

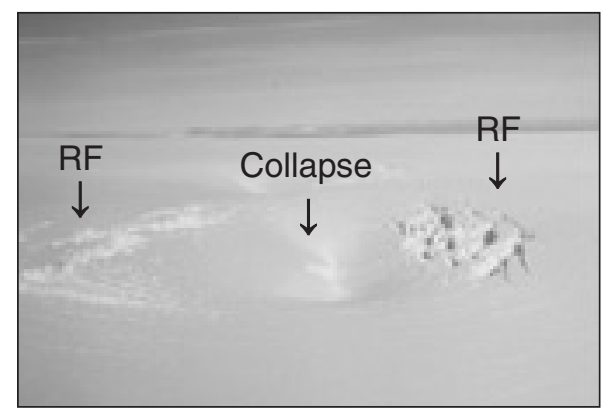

Figure 2. Vatnajökull subglacial eruption in October 1, 1996. Note 2-km-wide, 100-m-deep collapse structure. RF-ring fractures. From Halldórsson, 2000.

a consequence of the freezing of a global ocean. Unlike on Earth, where water progressively freezes into ice as temperatures drop during winter, on Europa an almost instantaneous solidification of water in the upper levels of the "ocean" is most probable. This would result from a sudden drop of temperature to $100 \mathrm{~K}$. How and why might such a catastrophic scenario develop? The answer might be provided by the major circular pattern in the anti-Jovian hemisphere of Europa. Greeley et al. (1998a; see their Fig. 9) suggested that this pattern may indicate the site of a major impact that led to basin formation in the silicate subcrust. The collision of more than 20 large fragments of comet ShoemakerLevy 9 with Jupiter on July 16-22, 1994, illustrated what scenario 2 might be. For example, impacts $A$ and $G$ struck Jupiter with an estimated energy equivalent to $22.5 \times 10^{4}$ and $6 \times 10^{6} \mathrm{MT}$, respectively, of TNT (Institute for Scientific Computation, 2000).

Either of scenarios 1 or 2 could lead to catastrophic ice melting and subsequent formation of glassy ice via extremely fast supercooling. A major question is whether glassy ice would develop a cracking pattern equivalent to that of perlitic glasses. The conditions are equivalent: abrupt drop in temperature and a liquid phase that will transform into an amorphous glassy solid. Under these conditions, we would expect the equivalent to quenching and perlite cracking in the icy material, only at much lower temperature. Even the "crystalline" Earth ocean ice is particularly sensitive to temperature changes; thermal cracking occurs when air temperature drops below water temperature under the ice sheet (Evans and Untersteiner, 1971; Evans, 1971). Although a definitive physical picture that explains the behavior of glassy water is still lacking (Debenedetti, 1998), we can approach the problem through the understanding of the thermodynamic behavior of liquid water undergoing cooling. If such cooling is fast enough (almost instantaneous), the process will be adiabatic; therefore, $Q$ (heat) $=0 \mathrm{~kJ}$. In other words, heat cannot be released. We have: 
$\delta Q=\delta U+\delta W$,

$C_{p} \delta T=C_{\nu} \delta T-P \delta V=0$,

$C_{v} \delta T=P \delta V$,

where $C_{p}=$ heat capacity at a constant pressure $(\mathrm{kJ} / \mathrm{K}), C_{v}=$ heat capacity at a constant volume $(\mathrm{kJ} / \mathrm{K}), \delta Q=C_{p} \delta T, \delta U=$ internal energy $=C_{\nu} \delta T$, $P=$ pressure $(\mathrm{Pa}), T=$ temperature $(\mathrm{K}), V=$ volume $\left(\mathrm{m}^{3}\right)$, and $\delta W=$ thermodynamic work $=$ $-P \delta V(\mathrm{~J})$. Given that $C_{v}$ and $P$ are constant, and $\left(T_{\text {final }}-T_{\text {initial }}\right)>>\left(V_{\text {final }}-V_{\text {initial }}\right)$ (superfast, supercooling process), it follows that the system will accommodate the excess of internal thermal energy in terms of cracking (release of mechanical energy). The same applies for an extruded molten rhyolitic magma subjected to extremely fast cooling (e.g., extrusion onto the seafloor; Yamagishi and Dimroth, 1985), which ultimately leads to formation of glassy volcanic materials. In addition, Knight (1987) described conspicuous arcuate contraction cracks in frozen slush (Fig. 3) that form in response to low diffusion rates of heat to the air. Thus, providing the cooling process was fast enough, there are no major reasons that preclude perlite-like cracking on Europa's ice (Fig. 1A and 1B). Scenarios 1 and 2 might provide the initial heat necessary to melt the icy envelope of Europa. The impact hypothesis is particularly appealing, however, because it is a high-energy instantaneous event.

\section{ICE CRACKING, BRINES, AND} MOVEMENT OF ICY PLATES

Sulfates may play a crucial role in the geologic evolution of Europa. Sullivan et al. (1998) called attention to the episodic icy plate separation and fracture infilling processes. They explained these phenomena in terms of plate fracturing and movement in response to regional surface stresses. This movement would allow the material to rise to the surface through the fractures. If the dark material

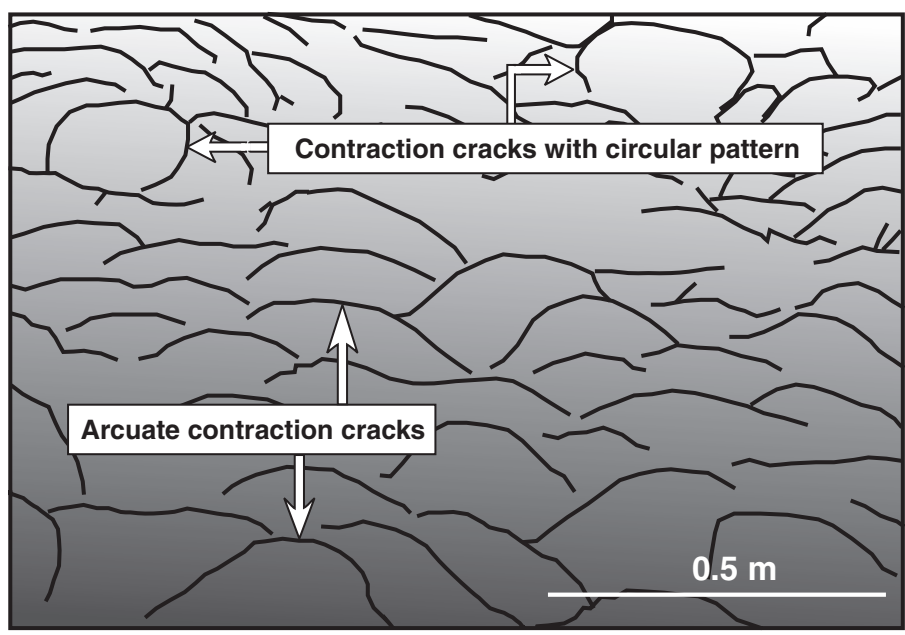

Figure 3. Contraction cracks in frozen slush (redrawn after Knight, 1987). observed in the images corresponds to sulfates of the type hexahydrite $\left(\mathrm{MgSO}_{4} \cdot 6 \mathrm{H}_{2} \mathrm{O}\right)$, epsomite $\left(\mathrm{MgSO}_{4} \cdot 7 \mathrm{H}_{2} \mathrm{O}\right.$ ), or similar species (McCord et al., 1998, 1999), the implications are enormous, because these minerals may exert strong crystallization pressures (e.g., to $290 \mathrm{MPa}$ during crystallization of epsomite; La Iglesia et al., 1996). We propose an alternative mechanism for sulfate emplacement along cracks. If glassy ice formation is fast enough, then salts may be retained in the ice; however, they would be eventually rejected because a brine has a higher density than ice (e.g., Greeley et al., 1998b). For Europa we suggest a process that could be termed "lateral draining of brines," toward a lower pressure environment, e.g., a crack connected to the surface (Fig. 4A). This process would be enhanced by the progressive ordering of the initially vitreous ice phase, which would result in higher crystallization pressure in the ice, and therefore, in salt rejection (Fig. 4A). If after the initial extremely fast supercooling of water in the upper levels, the process slowed, the remaining covered ocean would have become progressively enriched in salts. In this scenario we also envisage a progressive downwardfreezing front, leading to an increasing salt concentration in the remaining shrinking ocean. The brines could be pumped up in response to steep pressure gradients (e.g., Sibson et al., 1988). Such a process would be enhanced by deep-seated hydrothermal activity (e.g., McCord et al. 1998) and release of volatiles (e.g., Crawford and Stevenson, 1988). Finally, brine migration and salt crystallization along cracks (Fig. 4B) may provide a plausible mechanism for plate movement (Sullivan et al., 1998; Prockter et al., 1999) along these structures. In turn, different rates of salt crystallization could lead to different rates of fracture opening.

\section{CONCLUSIONS}

We suggest that ice melting followed by extremely fast supercooling of water, or water vapor, may have led to formation of glassy ice and associated cracking in the anti-Jovian region of Europa. To produce the energy required for the initial melting, we propose two possible scenarios: (1) subglacial massive volcanic activity, or (2) a large impact on the surface of the anti-Jovian region. Cracking of the newly formed vitreous ice can be explained by a sudden and dramatic drop in temperature - a minimum of about $173 \mathrm{~K}$ in the case of liquid water-which could have been even higher if the scenario included hot liquid water or hot water vapor. Subsequent movement along cracks and formation of new fractures could have been governed by brine emplacement and crystallization processes. Our model does not rule out other processes on Europa, such as remelting of ice or ice rafting, which could be sustained by hidden volcanic activity among other possible causes.

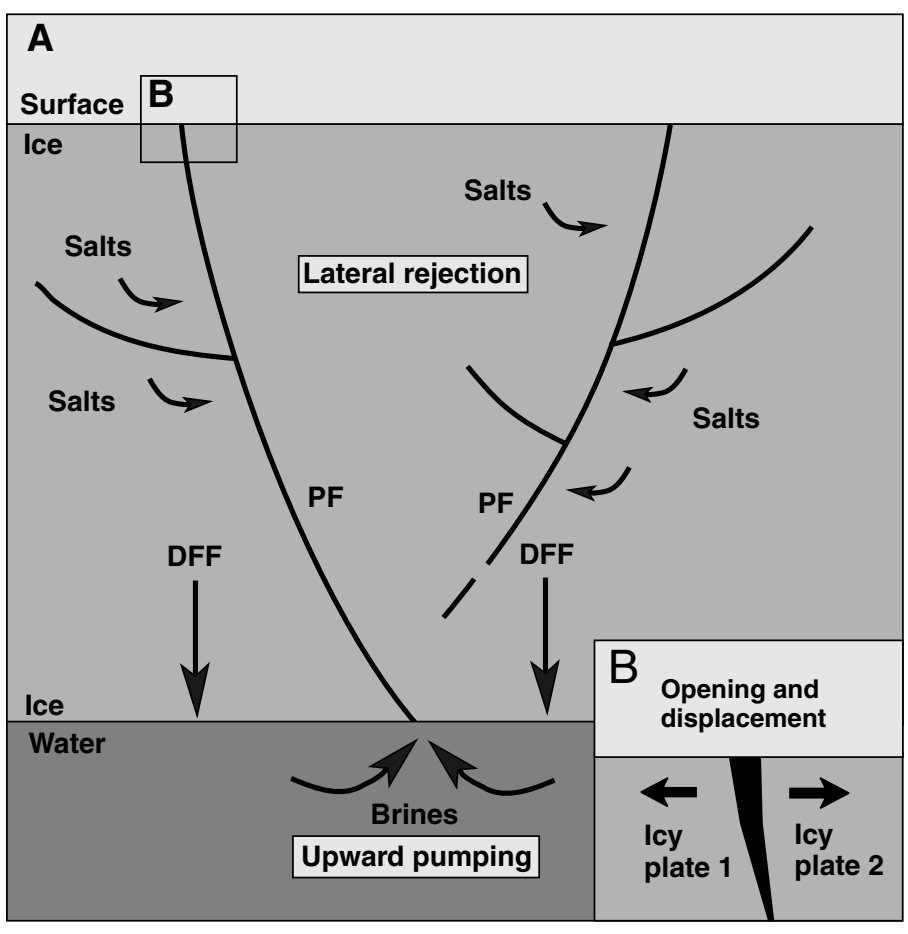

Figure 4. Sketch of cross section (not to scale) depicting possible pathways for brine migration along fractures. A: General view including salt rejection (lateral draining) and upward pumping of brines. DFFdownward-freezing front leading to brine concentration in shrinking ocean; PF-propagating fracture. B: Salt crystallization, increased fracture opening leading to plate separation (1 and 2). 


\section{ACKNOWLEDGMENTS}

We thank Jocelyn McPhie for providing photographs of perlite, Bettina Müschen and Christoph Böhm for providing information on the Bárdarbunga eruption, Mar de Ignacio for help with the thermodynamic aspects of thermal cracking, and Vicki Hansen for constructive comments on the paper.

\section{REFERENCES CITED}

Allen, R.L., 1988, False pyroclastic textures in altered silicic lavas, with implications for volcanicassociated mineralization: Economic Geology, v. 83 , p. $1424-1446$.

Bartenev, G.M., 1970, The structure and mechanical properties of inorganic glasses: Amsterdam, Wolters-Noordhoff Press, $246 \mathrm{p}$.

Carlson, R.W., Johnson, R.E., and Anderson, M.S., 1999, Sulfuric acid on Europa and the radiolytic sulfur cycle: Science, v. 286, p. 97-99.

Crawford, G.D., and Stevenson, D.J., 1988, Gas driven water volcanism and the resurfacing of Europa: Icarus, v. 73, p. 66-79.

Davis, B.K., and McPhie, J., 1996, Spherulites, quench fractures and relict perlite in a Late Devonian rhyolite dyke, Queensland, Australia: Journal of Volcanology and Geothermal Research, v. 71, p. $1-11$.

Debenedetti, P.G., 1998, One substance, two liquids? Nature, v. 392, p. 127-129.

Evans, R.J., 1971, Cracks in perennial sea ice due to thermally induced stress: Journal of Geophysical Research, v. 76, p. 8153-8157.

Evans, R.J., and Untersteiner, N., 1971, Thermal cracks in floating ice sheets: Journal of Geophysical Research, v. 76, p. 694-703.

Finnerty, A.A., Ransford, G.A., Pieri, D.C., and Collerson, K.D., 1981, Is Europa surface cracking due to thermal evolution?: Nature, v. 289, p. 24-27.

Friedman, I., and Smith, R.L., 1958, The deuterium content of water in some volcanic glasses: Geochimica et Cosmochimica Acta, v. 15, p. 218-228.

Greeley, R., Sullivan, R., Klemaszewski, J., Homan, K Head, J.W., Pappalardo, R.T., Veverka, J., Clark, B.E., Johnson, T.V., Klaasen, K.P., Belton, M., Moore, J., Asphaug, E., Carr, M.H., Neukum, G., Denk, T., Chapman, C.R., Pilcher, C., Geissler, P.E., Greenberg, R., and Tufts, R., 1998a, Europa: Initial Galileo geological observations: Icarus, v. 135, p. 4-24.

Greeley, R., Sullivan, R., Coon, M.D., Geissler, P.E., Tufts, R., Head, J.W., Pappalardo, R.T., and Moore, J.F., 1998b, Terrestrial sea ice morphology: Considerations for Europa: Icarus, v. 135, p. $25-40$.

Halldórsson, M.M., 2000, Subglacial volcanic eruptions at Vatnajökull: http://www.hi.is/ mmh/gos/; accessed June 2000

Helfenstein, P., and Parmentier, E.M., 1983, Patterns of fracture and tidal stresses on Europa: Icarus, v. 53, p. $415-430$.
Institute for Scientific Computation, 2000, Frequently asked questions about the collision of Comet Shoemaker-Levy 9 with Jupiter: http://www.isc. tamu.edu/ astro/s19/cometfaq2.html; accessed June 2000.

Jenniskens, P., Blake, D.F., Wilson, M.A., and Pohorille, A., 1995, High-density amorphous ice, the frost on interstellar grains: Astrophysical Journal, v. 455 , p. $389-401$.

Knight, C.A., 1987, Slush on lakes, in Loper, D.E., ed., Structure and dynamics of partially solidified systems: NATO ASI Series (E: Applied Sciences), no. 125 , p. $455-465$.

La Iglesia, A., González, V., López-Acebedo, V., and Viedma, C., 1996, Salt crystallization in porous construction materials I: Estimation of crystallization pressure: Journal of Crystal Growth, v. 177, p. 111-118.

Marshall, R.R., 1961, Devitrification of natural glass: Geological Society of America Bulletin, v. 72, p. 1493-1520.

McCord, T.B., Hansen, G.B., Fanale, F.P., Carlson, R.W., Matson, D.L., Johnson, T.V., Smythe, W.D., Crowley, J.K., Martin, P.D., Ocampo, A., Hibbitts, C.A., Granahan, J.C., and the NIMS Team, 1998, Salts on Europa's surface detected by Galileo's near infrared mapping spectrometer: Science, v. 280, p. 1242-1255.

McCord, T.B., Hansen, G.B., Matson, D.L., Johnson, T.V., Crowley, J.K., Fanale, F.P., Carlson, R.W., Smythe, W.D., Martin, P.D., Hibbitts, C.A., Granahan, J.C., and Ocampo, A., 1999, Hydrated salt minerals on Europa's surface from the Galileo near-infrared mapping spectrometer (NIMS) investigation: Journal of Geophysical Research, v. 104, p. 11,827-11,851.

McPhie, J., Doyle, M., and Allen, R., 1993, Volcanic textures: Hobart, Tasmania, CODES Key Centre Press, $196 \mathrm{p}$.

Mishima, O., and Stanley, H.E., 1998, The relationships between liquid, supercooled and glassy water: Nature, v. 396, p. 329-335.

Müschen, B., Böhm, C., Roth, A., Schwäbisch, M., and Reiniger, K.D., 1997, Application of ERS-1/2 SAR for monitoring of subglacial volcanic eruption and a following glacial flood in Iceland: Highlights, v. 2, p. 6-12.

Ojakangas, G.W., and Stevenson, D.J., 1989, Thermal state of an ice shell on Europa: Icarus, v. 81, p. $220-241$.
Poirier, J.P., 1982, Rheology of ices: A key to the tectonics of ice moons of Jupiter and Saturn: Nature, v. 299 , p. $683-688$

Prockter, L.M., Antman, A.M., Pappalardo, R.T., Head, J.H., and Collins, G.C., 1999, Europa: Stratigraphy and geologic history of the anti-Jovian region from Galileo E14 solid-state imaging data: Journal of Geophysical Research, v. 104, p. 16,531-16,540.

Ross, C.S., and Smith, R.L., 1955, Water and other volatiles in volcanic glasses: American Mineralogist, v. 40, p. 1071-1089.

Sibson, R.H., Robert, F., and Poulsen, K.H., 1988, High-angle reverse faults, fluid-pressure cycling, and mesothermal gold-quartz deposits: Geology, v. 16, p. $551-555$.

Students for the Exploration and Development of Space, 2000, Europa: http://seds.org/billa/tnp/ europa.html; accessed June 2000.

Sullivan, R., Greeley, R., Homan, K., Klemaszewski, J., Belton, M.J.S., Carr, M.H., Chapman, C.R., Tufts, R., Head, J.W., Pappalardo, R., Moore, J., Thomas, P., and the Galileo Imaging Team, 1998, Episodic plate separation and fracture infill on the surface of Europa: Nature, v. 391, p. 371-373.

Yamagishi, H., and Dimroth, E., 1985, A comparison of Miocene and Archean rhyolite and hyaloclastites: Evidence for a hot and fluid rhyolite lava: Journal of Volcanology and Geothermal Research, v. 23, p. 337-355.

Yamagishi, H., and Goto, Y., 1992, Cooling joints of subaqueous rhyolite lavas at Kuroiwa, Yakumo, southern Hokkaido, Japan: Volcanological Society of Japan Bulletin, v. 37, p. 205-207. 